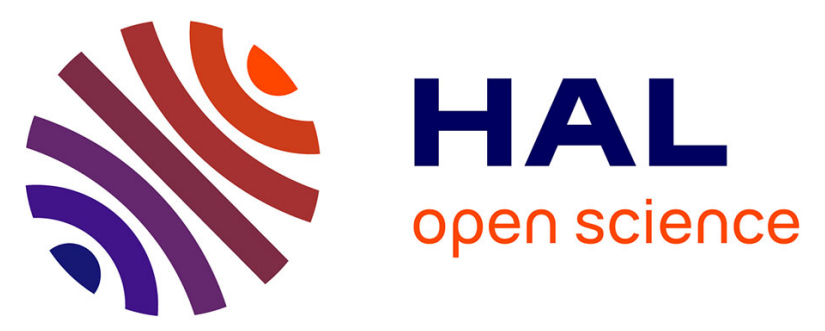

\title{
Design and integration of femtosecond fiber Bragg gratings temperature probes inside actively cooled ITER-like plasma-facing components
}

N Chanet, Y Corre, Romain Cotillard, J Gaspar, Guillaume Laffont, C Pocheau, G Caulier, C Dechelle, B de Gentile, C Destouches, et al.

\section{To cite this version:}

N Chanet, Y Corre, Romain Cotillard, J Gaspar, Guillaume Laffont, et al.. Design and integration of femtosecond fiber Bragg gratings temperature probes inside actively cooled ITER-like plasma-facing components. Fusion Engineering and Design, 2021, 166, pp.112376. 10.1016/j.fusengdes.2021.112376 . hal-03583704

\section{HAL Id: hal-03583704 \\ https://hal-amu.archives-ouvertes.fr/hal-03583704}

Submitted on 22 Feb 2022

HAL is a multi-disciplinary open access archive for the deposit and dissemination of scientific research documents, whether they are published or not. The documents may come from teaching and research institutions in France or abroad, or from public or private research centers.
L'archive ouverte pluridisciplinaire HAL, est destinée au dépôt et à la diffusion de documents scientifiques de niveau recherche, publiés ou non, émanant des établissements d'enseignement et de recherche français ou étrangers, des laboratoires publics ou privés.

\section{(1) (1) $\$$}

Distributed under a Creative Commons Attribution - NonCommercial - NoDerivatives 44.0 


\title{
Design and integration of femtosecond fiber Bragg gratings temperature probes inside actively cooled ITER-like plasma-facing components
}

\author{
N. Chanet ${ }^{\mathrm{a}}$, Y. Corre ${ }^{\mathrm{a}}$, R. Cotillard ${ }^{\mathrm{b}}$, J. Gaspar ${ }^{\mathrm{c}}$, G. Laffont ${ }^{\mathrm{b}}$, C. Pocheau ${ }^{\mathrm{a}}$, G. Caulier ${ }^{\mathrm{a}}$, C. Dechelle ${ }^{\mathrm{a}}$, B. \\ De Gentile ${ }^{\mathrm{a}}$, C. Destouches ${ }^{\mathrm{d}}$, F. Gallay ${ }^{\mathrm{a}}$, T. Gonzart ${ }^{\mathrm{a}}, \mathrm{C}_{\text {. Hernandez }}$, M. Missirlian ${ }^{\mathrm{a}}$, M. Richou ${ }^{\mathrm{a}}$, N. \\ Roussel $^{\text {b }}$ B. Santraine ${ }^{a}$ and the WEST team*
}

\author{
${ }^{\text {a }}$ CEA, IRFM, 13108 Saint-Paul-Lez-Durance, France \\ ${ }^{\mathrm{b}}$ CEA, List, Gif-sur-Yvettes cedex, 91191, France \\ ${ }^{c}$ Aix Marseille Univ, CNRS, IUSTI, Marseille, France \\ ${ }^{\mathrm{d}}$ CEA, DES/IRSENE/DER/SPESI, 13108 Saint-Paul-Lez-Durance, France \\ * See http://west.cea.fr/WESTteam
}

\begin{abstract}
Measuring the temperature in plasma-facing components (PFCs) provides information both on plasma parameters in the divertor region and on the thermal stress experienced by PFCs. Fiber Bragg gratings (FBGs) are interesting candidates for this application because they are immune to electromagnetic interferences and their ability to be multiplexed allows an extended spatial coverage. Four fibers, each of them including eleven regenerated Bragg gratings, have been embedded in tungsten-coated graphite components and operated up to their signal-collapsing limit at $800^{\circ} \mathrm{C}$. Extending the measurement range towards higher temperatures increases the sensitivity to plasma parameters and allows withstanding higher energy experiments. To overcome thermal limitations, the system is up-graded using femtosecond laser inscribed fibers. In addition to their outstanding thermal stability, femtosecond FBGs benefit from higher signal-to-noise ratios than regenerated FBGs. The paper addresses femtosecond FBGs design and issues relative to their integration inside the actively cooled ITER-like PFCs of the WEST tokamak. Gratings period and length is designed to increase the number of measurement spots to fourteen gratings per fiber, regularly distributed over $17 \mathrm{~cm}$, while ensuring robust detection even with strong thermal gradients (no overlapping or deformation of Bragg peaks). The system operates up to $1200^{\circ} \mathrm{C}$ with gradients reaching $200^{\circ} \mathrm{C} / \mathrm{mm}$ perpendicularly and $40^{\circ} \mathrm{C} / \mathrm{mm}$ in parallel to the fiber. FBGs are inserted in actively cooled ITER-like PFCs through a $2.5 \mathrm{~mm}$ deep lateral groove localized at $5 \mathrm{~mm}$ beneath the top of bulk tungsten mono-blocks. A PFC mock-up machined with a groove has been tested under HHF facility to assess the effect of the groove on mono-blocks thermal behavior. The test demonstrates that machined mono-blocks behave as expected from simulation and can withstand 20 $\mathrm{MW} / \mathrm{m}^{2}$ heat flux (i.e. $1200^{\circ} \mathrm{C}$ in the fiber) with $20 \%$ overheating as compared to intact mono-blocks.
\end{abstract}

\section{Introduction}

Measuring temperature in plasma-facing components (PFCs) allows for the estimation of heat flux in the divertor region. The interest is twofold since it provides information both on plasma parameters and on the thermal stress experienced by PFCs. When considering this application in the scope of contact temperature sensors, Fiber Bragg Gratings (FBGs) stands out from thermocouples as they are immune to electromagnetic interference and they have the ability to be multiplexed inside a single optical fiber [1]. Multiplexing FBGs is performed in the frequency domain, equivalently expressed in terms of 
wavelength. This feature offers the possibility to spread multiple measurement spots along a single fiber thus saving space and extending the spatial coverage. To date, four optical fibers each of them including eleven FBGs have been used during plasma operation in the lower divertor of the WEST tokamak [2]. These FBGs have been embedded in tungsten-coated graphite PFCs [3] and heated above $400^{\circ} \mathrm{C}$ in a tokamak environment for approximately 110 plasma pulses. As the full divertor of WEST is now replaced by actively cooled ITER-like PFCs designed for steady-state operation up to $20 \mathrm{MW} / \mathrm{m}^{2}$, thermal constraints in PFCs are modified and the FBG integration must be upgraded accordingly. In parallel to the transformation occurring in WEST, scientists from the EAST tokamak have installed FBGs in a PFC mock-up of similar technology and tested their FBG based temperature monitoring system in a high heat flux facility [4]. The integration of FBGs requires additional machining on the ITER-like PFCs, especially in their bulk tungsten part, which raises concerns whether the modified PFC would still comply with heat exhaust requirements. Another concern is the mechanical fixation between the PFC and the fiber, which requires revision and evaluation in terms of thermal response. Regarding FBGs design, the gratings inscription technology has changed as compared to the previous generation of FBG used in WEST. Gratings are now inscribed with the femtosecond laser technology offering outstanding thermal resistance, higher signal-to-noise ratio and easier control on the grating length. These features are used advantageously to limit the thermal gradients related artifacts observed on the previous generation of FBGs. This paper addresses femtosecond FBGs design and issues relative to their integration inside the actively cooled ITER-like PFCs of the WEST tokamak. The thermal behavior of the modified PFC is numerically simulated and tested in a high heat flux (HHF) facility (Section 2). Potential defects induced by the HHF test on the PFC structure and on the FBG fixation are evaluated using respectively infrared non-destructive control of the components [5] and the thermal response probed at the FBG location. The FBGs integration in the WEST lower divertor is presented in section 3. The noise level on temperature measurements as well as the calibration curve of femtosecond FBG are measured and compared to the previous generation of FBGs. Finally (section 4), we have adapted the design of FBGs to the specific environment present in a tokamak divertor where thermal gradients are particularly high along the optical fiber. We propose a theoretical explanation and a practical method to mitigate the measurement artifacts related to temperature gradients. Gratings position, period and length is designed to maximize the number of measurement spots per fiber while ensuring robust detection (no thermal degradation nor overlapping or deformation of Bragg peaks) regarding the thermal constraints encountered with ITER-like PFCs during plasma operation.

\section{Thermal behavior of the modified plasma facing components}

\subsection{Modifications on plasma facing components}

The actively cooled tungsten (W) Plasma Facing Unit (PFU) used in the WEST tokamak is representative of the ITER divertor [6,7] as it uses the same technology to withstand continuous heat loads on the order of $20 \mathrm{MW} / \mathrm{m}^{2}$. In WEST, each PFU is composed of 35 tungsten monoblocks of individual size $28 \mathrm{~mm}$ x $12 \mathrm{~mm}$ x $26 \mathrm{~mm}$ (width x depth x height) assembled with a gap of $0.5 \mathrm{~mm}$ on a $\mathrm{CuCrZr}$ heat sink tube. The tube is centered at $14.5 \mathrm{~mm}$ below the surface exposed to heat flux. Its diameter and thickness are respectively $12 \mathrm{~mm}$ and $1.5 \mathrm{~mm}$ [2]. A CuOFHC interlayer of $1 \mathrm{~mm}$ thickness is placed between the tube and the tungsten. Active cooling is performed with water at $70^{\circ} \mathrm{C}, 3 \mathrm{MPa}$ pressure, flowing inside the tube. To integrate an optical fiber, the PFU is machined with a groove using electro erosion technique (cf. Figure 14). The groove is running along the PFU lateral face at $5 \mathrm{~mm}$ below the surface exposed to heat flux. The optical fiber having $1 \mathrm{~mm}$ diameter, the width of the groove is $1.2 \mathrm{~mm}$ and its depth is $2.5 \mathrm{~mm}$ terminated by a half circle centered at $2.5 \mathrm{~mm}$ depth to fit with the fiber shape. 


\subsection{Thermal simulation}

The finite element calculation presented in Figure 1 shows the isotherms obtained on the instrumented monoblock once thermal equilibrium is reached. Calculation was performed with ANSYS by taking into account the dependance of materials properties with temperature [8], assuming $20 \mathrm{MW} / \mathrm{m}^{2}$ uniform heat flux on the top surface, which is the highest specified value for such PFC. The lateral groove hinders heat propagation through the monoblock (from the top surface to the tube) leading to overheating as compared to a standard monoblock (without the groove) exhausting the same heat load. Assuming the groove is empty, i.e. without FBG probe and ceramic adhesive inside, the maximum surface temperature is expected to be $400^{\circ} \mathrm{C}$ higher in the presence of the groove for the extreme heat load presented in Figure 1, which corresponds to $20 \%$ local overheating as compared to an intact monoblock. With the FBG probe installed and the ceramic adhesive filling the groove, this local overheating is lowered.

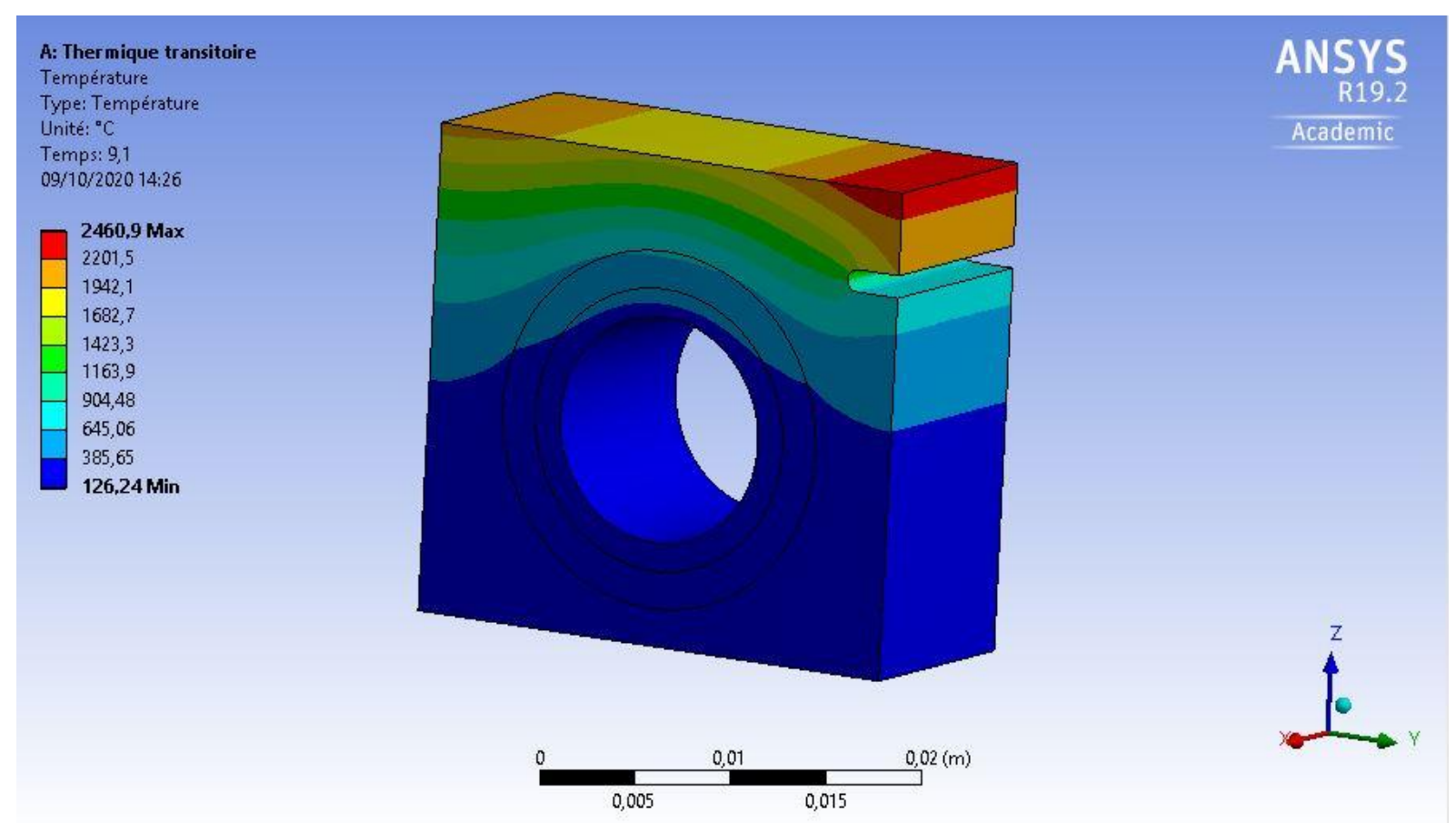

Figure 1: Isotherms at steady state computed for a single monoblock with $20 \mathrm{MW} / \mathrm{m}^{2}$ uniform heat flux applied on the top surface.

\subsection{High heat flux test}

To assess the thermomechanical integrity of the instrumented monoblock, a high heat flux (HHF) test program was conducted at the Research Centre Rež (CVR) located in Czech Republic. CVR operates an electron beam gun HHF test facility called HELCZA [9]. A full-scale mock-up component comprising seven actively cooled bulk tungsten-monoblocks (ITER-like) have been specifically designed to test the thermal behavior of the instrumented monoblocks, with machined lateral grooves. One-millimeter size thermocouples have been inserted and fixed with a high temperature ceramic adhesive (Ceramabond 571-VFG, Aremco) in order to monitor the temperature inside the groove. The objective is to assess the effect of the instrumented groove when undergoing HHF cycling up to prescribed $20 \mathrm{MW} / \mathrm{m}^{2}$. 


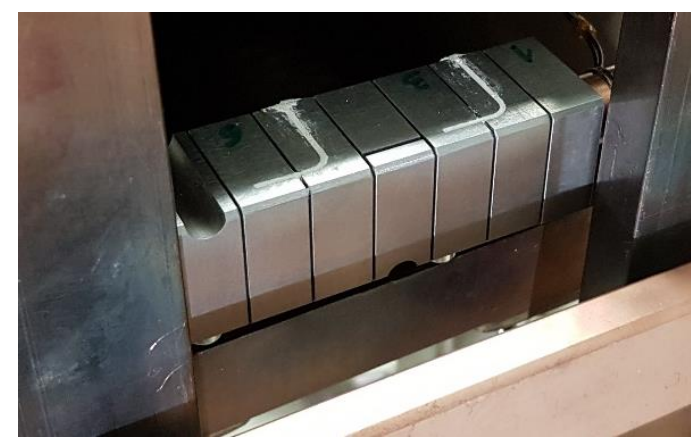

Figure 2: Seven actively cooled monoblocks (numbered from 1 to 7 from right to left) facing the electron beam gun of HELCZA HHF facility and framed by movable shielding screens. An empty lateral groove located at $5 \mathrm{~mm}$ beneath the surface exposed to heat flux is visible on the monoblock 4 (central). The paths of the two thermocouples wires running across monoblocks 2-3 and 5-6 are visible through the white marking of the glue. The probing spots of the thermocouples are located respectively on monoblocks 3 and 6 at $5 \mathrm{~mm}$ beneath the exposed surface.

The mock-up overall length was $87 \mathrm{~mm}$ including $0.5 \mathrm{~mm}$ gaps between individual monoblocks. Monoblocks were machined using electro erosion technique. The groove characteristics were $1.2 \mathrm{~mm}$ wide, $2.5 \mathrm{~mm}$ deep terminated by a half circle centered at a depth of $2.5 \mathrm{~mm}$. The groove middle plane was located at $5 \mathrm{~mm}$ beneath the surface exposed to heat flux. Each monoblock had its proper layout (cf. Figure 2): Monoblock number 4 contained an empty groove allowing for visual examination and the investigation of potential cracks formation in tungsten. Monoblocks number 1, 3 and 6 contained a thermocouple embedded inside the groove having similar characteristics as for monoblock 4 except that it did not covers the complete monoblock width. Thermocouples were fixed inside these grooves using a high temperature ceramic adhesive (Ceramabond 571-VFG, Aremco).

During the test, the mock-up was actively cooled with water flowing at a rate of $3.7 \mathrm{~m}^{3} / \mathrm{h} \pm 5 \%$ (i.e. 9 $\mathrm{m} / \mathrm{s}$ velocity inside the tube) and a pressure of $24.9 \pm 0.5$ bar. The water inlet temperature was regulated at $70{ }^{\circ} \mathrm{C} \pm 10 \%$. Calorimetry measurements were performed from the temperature difference between an inlet and an outlet temperature probe, located inside the water-cooling channel and placed respectively just before and after the mock-up installation.

The mock-up was tilted by $9.5^{\circ}$ with respect to the electron beam axis in order to shadow the cooling tube otherwise directly exposed to the incident heat flux running across inter monoblock gaps. Similarly, to shadow the thermocouples from direct incident beam, the mock-up was rotated by an angle of $5^{\circ}$ around the tube axis. The superposition of $9.5^{\circ}$ tilt and $5^{\circ}$ rotation resulted in $10.7^{\circ}$ angle between the mock-up surface exposed to heat flux and the incident electron beam axis. Additionally, movable shielding screens could selectively cover individual monoblock. The surface area effectively exposed to the electron beam was calculated for different shielding frame configurations leading to $2384 \mathrm{~mm}^{2}$ exposure surface when monoblocks 1 to 7 were uncovered, $2029 \mathrm{~mm}^{2}$ when monoblocks 2 to 7 were uncovered, $1007 \mathrm{~mm}^{2}$ when monoblocks 5 to 7 were uncovered and $1040 \mathrm{~mm}^{2}$ when monoblocks 2 to 4 were uncovered. The contribution of backscattering electrons from the shielding screens onto the mock-up was taken into account in the effective area calculation yet it was evaluated to have a smaller contribution than the area of a single monoblock [10]. The effective surface area together with calorimetry measurements allowed for heat flux estimation.

To ensure that the flux is uniform, the bremsstrahlung radiations were observed with an X-ray camera showing less than $\pm 10 \%$ heat flux variations onto the mock-up surface. 
Temperatures of the exposed surface were measured using infrared diagnostics: one pyrometer (PA40 $\mathrm{AF} 4 / \mathrm{C}$, Keller, wavelengths $0.95 \mu \mathrm{m}$ and $1.05 \mu \mathrm{m}$ allowing measurement in the $750-2400{ }^{\circ} \mathrm{C}$ temperature range) and one infrared camera (FLIR SC8203, wavelength $3-5 \mu \mathrm{m}, 1024 \times 1024$ pixels). The pyrometer provided an average temperature over a targeted spot size of about $10 \mathrm{~mm}$. The emissivity of the infrared camera was calculated based on temperature records from the pyrometer.

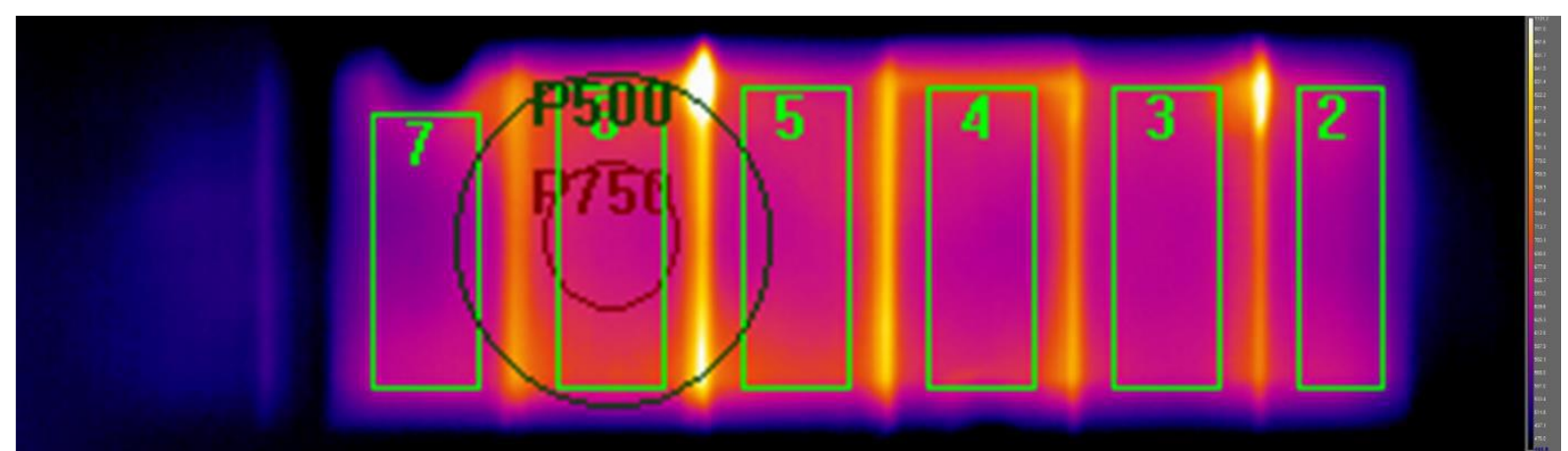

Figure 3: Infrared image of the mock-up surface exposed to $6 \mathrm{MW} / \mathrm{m}^{2}$ heat flux. The temperature recorded by the pyrometer is averaged over the region circumscribed by the circle labelled P750.

Another way to estimate the heat flux is to compare temperature measurements (pyrometer on top surface and embedded thermocouples at $5 \mathrm{~mm}$ below the surface) with numerical simulation at steady state. The heat flux estimated from calorimetry is found to be higher by a factor of 1.6 as compared to the estimation based on pyrometry and embedded thermocouples. The heat flux values reported in this article are systematically divided by 1.6 if they were estimated from calorimetry in order to report consistent values with the estimation based on pyrometry and thermocouples. The instrumented mockup was first heated during 3 minutes (Step 1, Figure 4) with a flux intensity of $3 \mathrm{MW} / \mathrm{m}^{2}$ to test the mock-up and beam gun installation. Each individual monoblock was then submitted to a series of heating cycles listed in Figure 4. The maximum flux experienced by monoblocks 2 to 4 is $20 \mathrm{MW} / \mathrm{m}^{2}$ and by monoblocks 5 to 7 is $12 \mathrm{MW} / \mathrm{m}^{2}$.

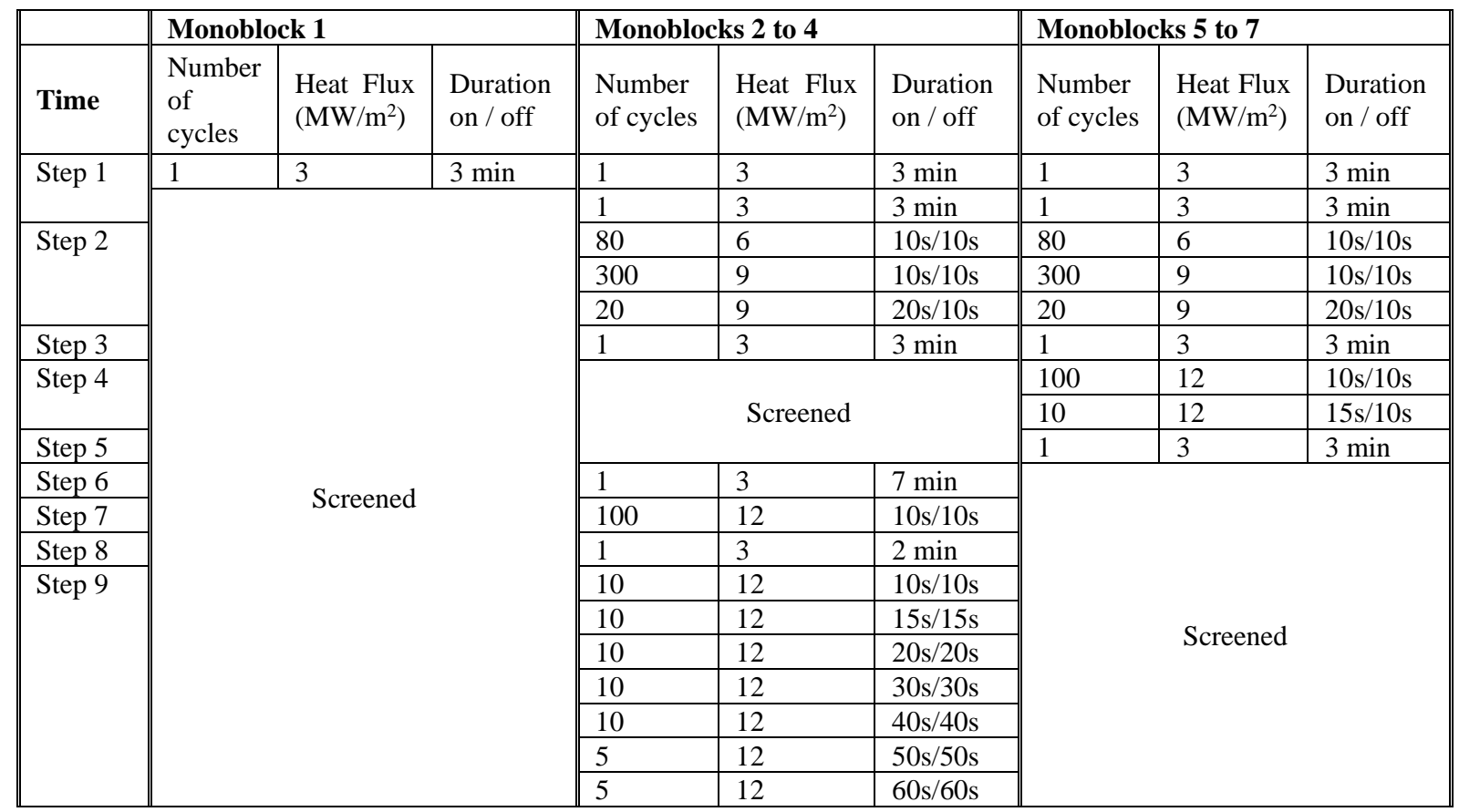




\begin{tabular}{|c|c|c|c|}
\hline Step 10 & 7 & $\begin{array}{l}\text { Gradually } \\
12 \text { to } 20\end{array}$ & $60 \mathrm{~s}$ \\
\hline Step 11 & 1 & 3 & $7 \mathrm{~min}$ \\
\hline
\end{tabular}

Figure 4: Series of HHF cycles performed for each monoblock.

The steady state temperature recorded from pyrometry (red dots) and embedded thermocouples (green cross) are plotted in Figure 5 as a function of the heat flux estimated from calorimetry. Except for the first two thermocouple measurements (step 6 and 8), the temperature scales linearly with the heat flux intensity as expected from numerical simulation. In particular, the ratio between measurements performed on top surface (pyrometers) and measurements performed at $5 \mathrm{~mm}$ below the surface (thermocouples) agrees with numerical simulation.

The steady state temperature given by the thermocouple (Figure 5, green crosses) shows stronger fluctuations as a function of the heat flux intensity as compared to pyrometry (Figure 5, red dots). This suggests some changes in the thermal behavior of the glue or at the interface between the glue and tungsten or between the glue and stainless steel, occurring in between each heating cycle.

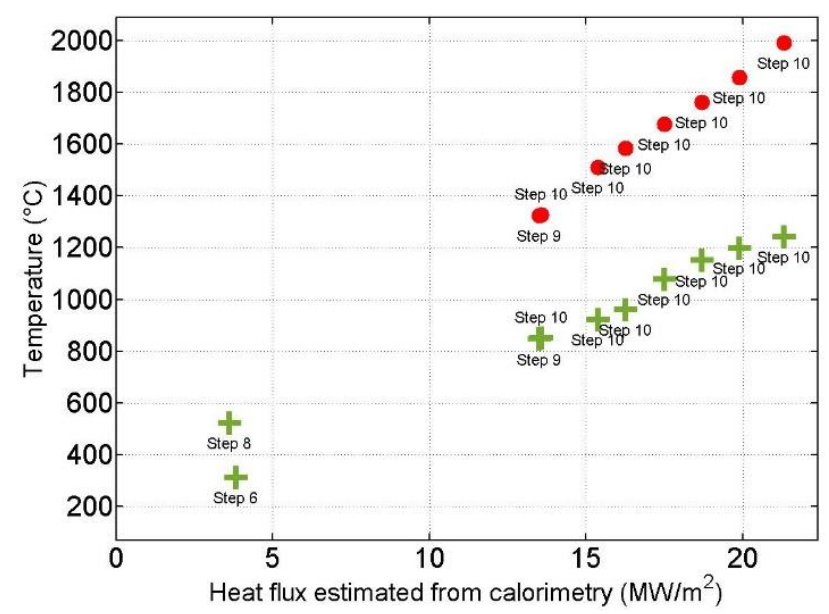

Figure 5: Temperature measurements on monoblock 3 as a function of heat flux estimated from calorimetry at steady state during Step 6, Step 8, Step 9 and Step 10. (Red dot) Pyrometry measurements. (Green cross) Thermocouple measurements. 

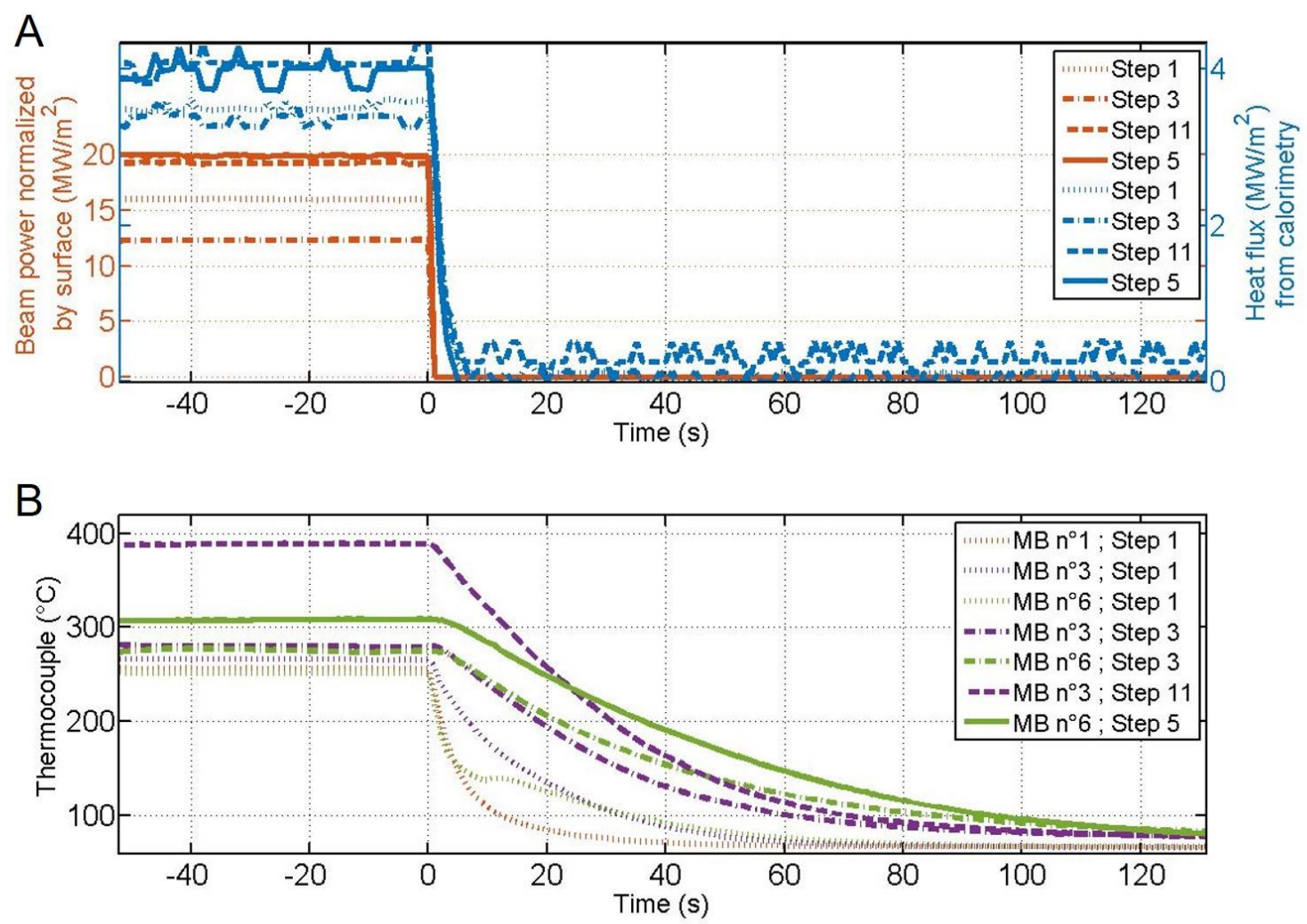

Figure 6: (A) Heat flux steps generated from the electron beam gun and time evolution of the flux absorbed in cooling water. (B) Temperature evolution of the thermocouples located on (purple) monoblock 3 and (green) monoblock 6 during the heat flux steps. (Dotted line) Evolution during Step 1 of the HHF schedule. (Dotted dashed line) Evolution during Step 3. (Dashed line) Evolution during Step 11. (Solid line) Evolution during Step 5.

The decay of the calorimetry measurements shown in Figure 6-A allows to estimate monoblocks time response to approximately $3 \mathrm{~s}$ (time required to reach $37 \%$ of their amplitude, i.e. assuming an exponential decay). This time response remains unchanged until the HHF test has been completed, indicating that monoblocks thermal behavior is not altered by the HHF test. No major failure or reduction of the heat exhaust capabilities due to the instrumented groove have been observed. However, one can notice that the time response of thermocouples is much longer than the time response of the rest of the monoblock.

Figure 6-B shows that the thermal time response of the two thermocouples located on monoblocks 3 and 6 increases during the HHF test, particularly between Step 1 and Step 3 (cf. Figure 4 for the scheduled Steps). Their time response defined as the time required to reach $37 \%$ of their amplitude, i.e. assuming an exponential decay, has increased from $18 \mathrm{~s}$ to $32 \mathrm{~s}$ for the thermocouple located on monoblock 3 and from $16 \mathrm{~s}$ to $40 \mathrm{~s}$ for the thermocouple located on monoblock 6. During Step 2, these monoblocks have experienced few hundred of heating cycles around $9 \mathrm{MW} / \mathrm{m}^{2}$. Between Step 3 and Step 5, the time response of the thermocouple located on monoblock 6 has further increased from $40 \mathrm{~s}$ to $52 \mathrm{~s}$. Between Step 3 and Step 11, the time response of the thermocouple located on monoblock 3 remains unchanged although it has experienced $20 \mathrm{MW} / \mathrm{m} 2$ during Step 10. The time response of the thermocouple located on monoblock 1 is $6 \mathrm{~s}$ which is shorter than the time response of the two other thermocouples even for a similar heat flux exposure (Step 1).

The temperature evolution of the thermocouple located on monoblock 6 shows a bump during its decay. This sudden change in thermal behavior is likely due to a change in the adhesion of the glue. 

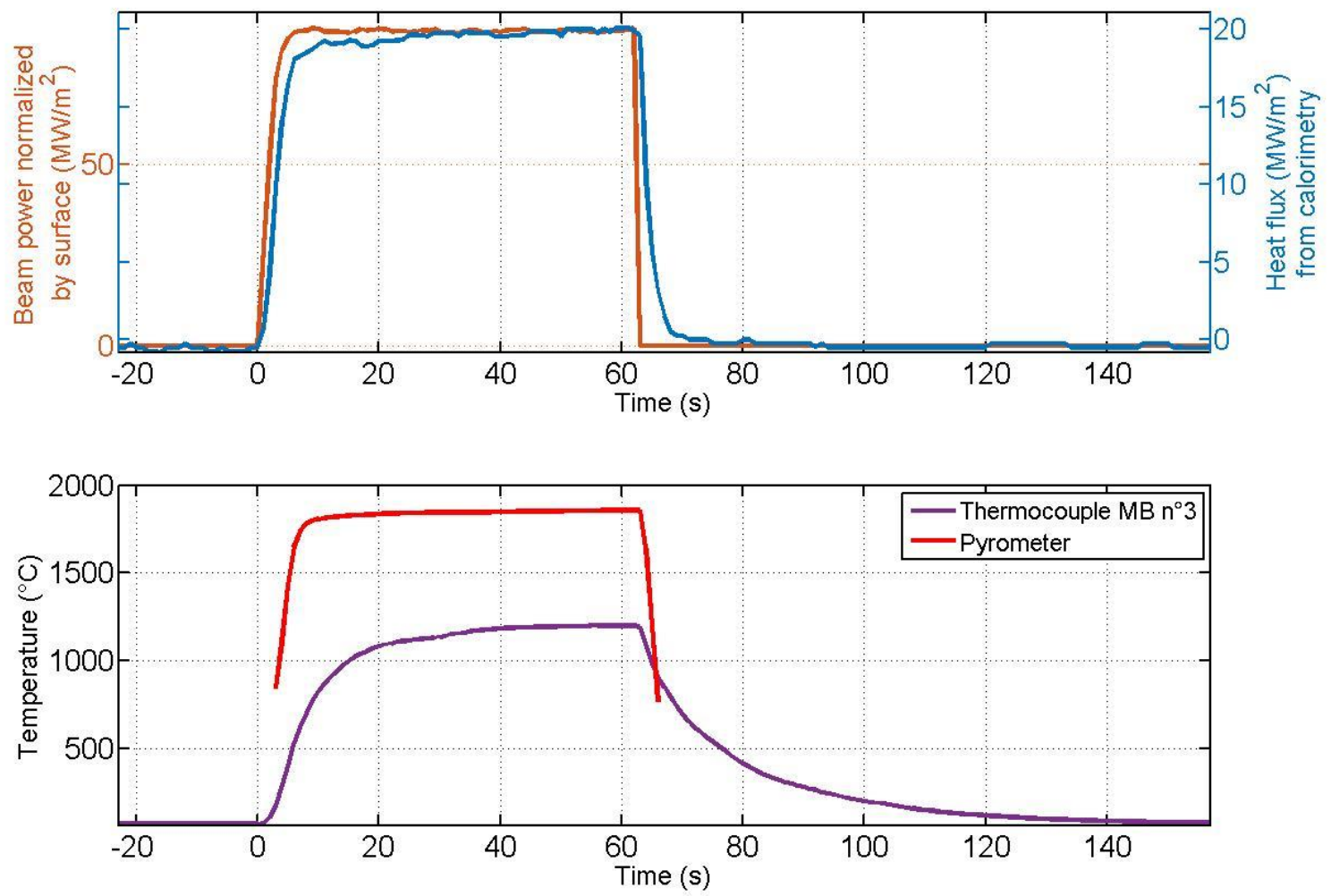

Figure 7: Temperature evolution of the (red) pyrometer and the (purple) thermocouple located on monoblock 3 during a heat flux step during Step 10 of the $\mathrm{HHF}$ schedule. The measurement range of the pyrometer is comprised between $750^{\circ} \mathrm{C}$ and $2400^{\circ} \mathrm{C}$.

Figure 7 shows the thermal response of the monoblock number 3 recorded with calorimetry and pyrometry (the pyrometer measurement range is comprised between $750^{\circ} \mathrm{C}$ and $2400^{\circ} \mathrm{C}$ ). The time response obtained with calorimetry and pyrometry (approximately $3 \mathrm{~s}$ ) is much shorter than the one obtained with the thermocouple.

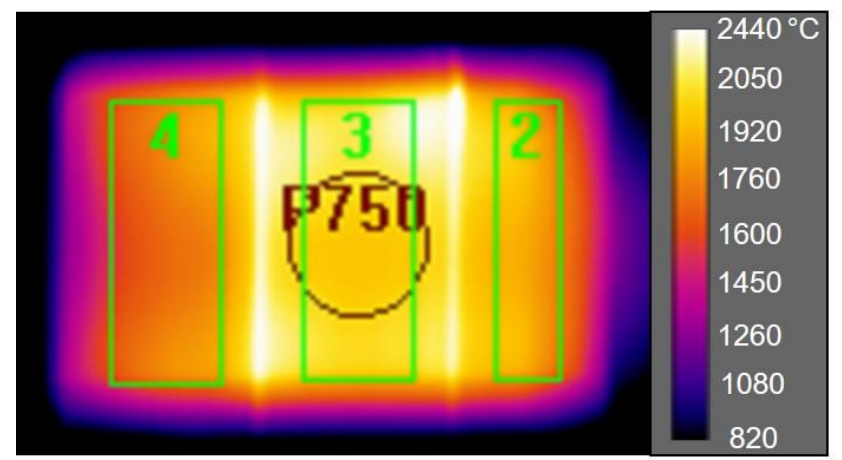

Figure 8: Infrared image of the surface of the monoblocks 2 to 4 exposed to heat flux during Step 10 at $20 \mathrm{MW} / \mathrm{m}^{2}$. The positioning of the pyrometer region of interest is marked by the circle labelled P750. Note that the scale on the color bar is not linear.

Figure 8 is an infrared image taken during $20 \mathrm{MW} / \mathrm{m}^{2}$ heat flux exposition. An emissivity of 0.1969 is used for the temperature calculation in order to match the surface temperature given by the pyrometer. The monoblock 3 appears to be hotter in the top right corner $\left(\approx 2400^{\circ} \mathrm{C}\right)$ near the thermocouple location (cf. Figure 2 for thermocouple location) as compared to the other corners $\left(\approx 2000^{\circ} \mathrm{C}\right)$. This overheating 
do not exceed $20 \%$ as compared to an intact monoblock (i.e. without thermocouple) which is in accordance with numerical simulation.

No visible damage is observed on the instrumented monoblocks after thermal loading. Microscopic inspection (magnification x100) performed on the monoblock 4 especially inside the empty groove do not show any cracks or different surface aspects following the HHF test.

The inspection at the thermocouples location showed that parts of the glue has cracked and detached on monoblock 3 making the thermocouple lead visible and that the glue on monoblock 6 has cracked.

\subsection{Non-destructive damage analysis}

The potential damages of the instrumented mock-up component generated by the HHF thermal loading was then assessed with the non-destructive SATIR (French acronym for infrared acquisition and data processing device) facility. The SATIR facility was CEA (Cadarache, France) to evaluate the thermal exhaust capabilities of actively cooled PFCs [5]. This test is based on the thermal transient response of PFCs submitted to forced convection. PFCs are initially thermalized at $100{ }^{\circ} \mathrm{C}$ by adjusting the water temperature flowing in the channel to $100{ }^{\circ} \mathrm{C}$. A cold water front is then created in the water flowing through the channel (water temperature varies from $100{ }^{\circ} \mathrm{C}$ to $10{ }^{\circ} \mathrm{C}$ within few milliseconds) to induce a thermal transient in the PFC similar to a quench water experiment. The temperature evolution could be recorded by IR thermography or with embedded thermocouples. In case of IR measurements, emissivity variations on the PFC surface are corrected by means of pixel normalization when the surface is thermalized at $100^{\circ} \mathrm{C}$ [11]. When measured with IR thermography, the time response is sensitive to defects hindering heat propagation through the PFC. An infrared camera was used to detect zones where the heat exhaust efficiency was not guaranteed. When measured with embedded thermocouples, the glue surrounding the thermocouple as well as the thermocouple itself induce an additional contribution to the PFC time response. The time response is defined as the decay time required to reach $37 \%$ of the total temperature variation, i.e. assuming an exponential decay. Alternatively, we use the maximum temperature difference observed during the temperature evolution to compare different experiments in terms of time response.

Three successive tests were conducted to monitor the mock-up thermal behavior: one before the mockup machining, one prior to the HHF test and one after the HHF test.

Results presented in Figure 9 show that the time response before machining is comprised between $2 \mathrm{~s}$ and $3 \mathrm{~s}$ for each monoblock which is consistent with calorimetry and pyrometry measurements performed during the HHF test facility (HELCZA). The maximum temperature elevation recorded before and after the high heat flux test did not exceed $8{ }^{\circ} \mathrm{C}$ as compared to the experiment performed before machining, meaning that the time response did not increase for more than $15 \%$. With such a small thermal delay, we can infer that the impact of embedded diagnostics on the mock-up transient response is negligible. 


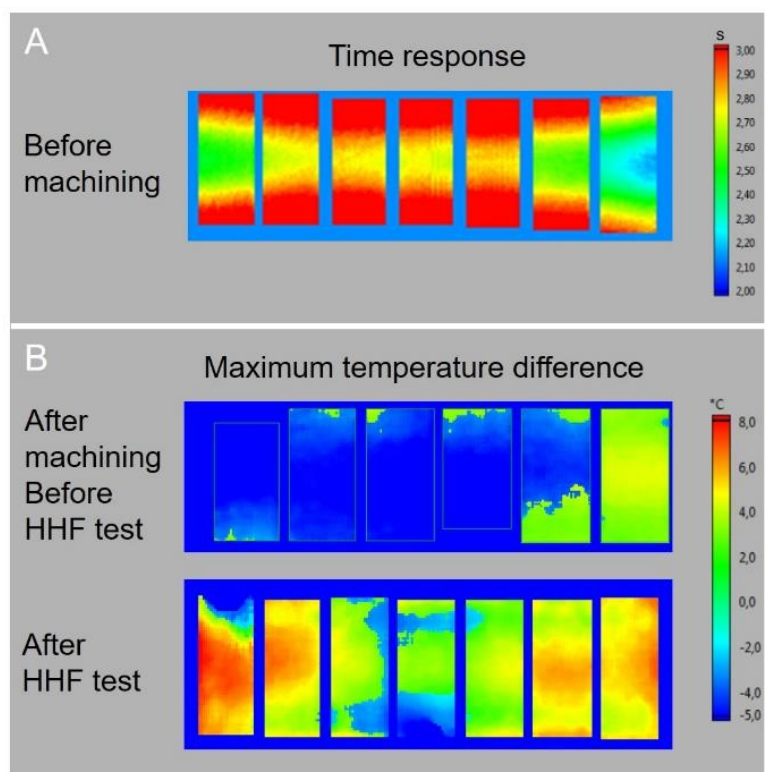

Figure 9: Measurements performed in the SATIR facility with the IR camera targeting the monoblocks top surface. (A) Time response of the mock-up component before machining. (B) Maximum temperature difference in time as compared to A before and after the High Heat Flux test.

The temperature evolution of embedded thermocouples submitted to SATIR tests is displayed in Figure 10. The temperature evolution accounts for the time response of the monoblock as well as the additional time responses of the glue and the thermocouple. For the pre HHF test experiment, the time response of the glue and the thermocouples is small as compared to the monoblocks time response while for the post HHF experiment, the time response of the thermocouples located on monoblock 3 and 6 has increased to approximately $1.5 \mathrm{~s}$. The increase in time response associated with the thermocouple located on monoblock 1 is noticeable yet it is smaller than the other thermocouples. It is unclear if this small increase is due to the glue or to the monoblock alteration. This result shows that a heat flux exposure higher than $3 \mathrm{MW} / \mathrm{m}^{2}$ alters significantly the thermal transfer between the monoblock and the thermocouple.

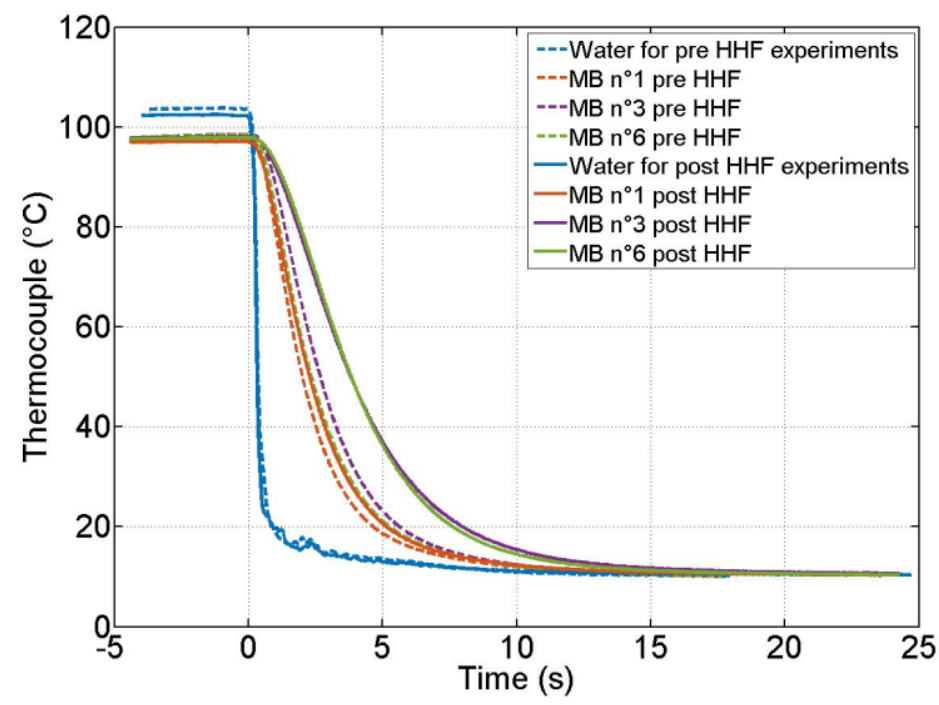

Figure 10: Temperature evolution of water and embedded thermocouples during a SATIR experiment. A first experiment is performed before the HHF test and a second is performed after the HHF test.

It is worth noting that the time responses measured during the SATIR experiment is not consistent with the time response measured during the HHF test. They are at least 20 times longer for the HHF test. 
While the HHF test is performed under vacuum, the SATIR test is performed at atmospheric pressure. This suggests that the absence of air in the glue or at the interface between glue and tungsten or glue and stainless steel may significantly decrease heat transfer between the monoblock and the thermocouple.

\section{FBGs design and integration in the WEST lower divertor}

\subsection{FBGs inscription and calibration}

Fiber Bragg Gratings (FBGs) are inscribed in the core of a single mode optical fiber using a femtosecond laser. The laser power allows to create a local damage on the micron scale which could be reproduced along the fiber to create a periodic index modulation as shown in Figure 11. This technology offers the possibility to control the length of each grating and prevents gratings from thermal erasure up to 1200 ${ }^{\circ} \mathrm{C}$.

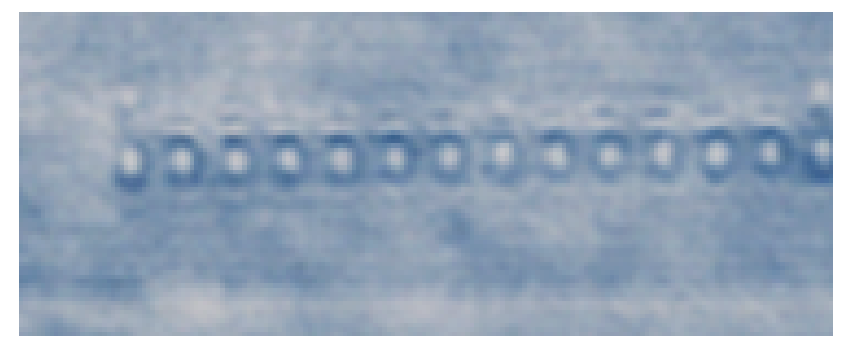

Figure 11 : Picture taken under microscope of a Bragg grating inscribed with a femtosecond laser in the fiber core. The pitch between each bubble is $0.5 \mu \mathrm{m}$.

The spectral row data are collected and demultiplexed with an FBG interrogator allowing for the simultaneous temperature acquisition of 8 optical fibers at a rate of $10 \mathrm{~Hz}$. As shown in Figure 12, the spectral range is $1460 \mathrm{~nm}$ to $1620 \mathrm{~nm}$ with a resolution of $8 \mathrm{pm}$. Each Bragg peak corresponds to one measurement spot along the fiber. The interrogator processes the peak tracking functionality and the conversion to temperature internally. The dependence of the Bragg peak position as a function of temperature is calibrated by introducing FBGs inside a furnace and by following their temperature with thermocouples installed in their vicinity.

Typical spectra obtained with femtosecond inscribed FBGs and with the previous generation of FBGs (already used during plasma operation in WEST) are displayed in Figure 12. The signal magnitude (in terms of light radiant power) obtained with the femtosecond technology is one thousand time higher than with the previous generation of FBGs which are inscribed based on the technological process of regeneration. The signal magnitude obtained with the previous generation is close to the baseline fluctuation level as shown in Figure 12. Previous experience showed that the baseline fluctuates when the temperature varies which introduces some oscillatory artifacts during peak tracking. Due to these oscillations, the error on temperature measurements reaches approximately $\pm 1{ }^{\circ} \mathrm{C}$ which otherwise would drop down to the detection noise level at $\pm 0.02{ }^{\circ} \mathrm{C}$. Regarding femtosecond FBGs, baseline fluctuations have no measurable influence on temperature measurements since the signal magnitude is much higher than previous generation FBGs. Femtosecond FBGs offers the possibility to reach a true \pm $0.02{ }^{\circ} \mathrm{C}$ error on temperature measurements. 


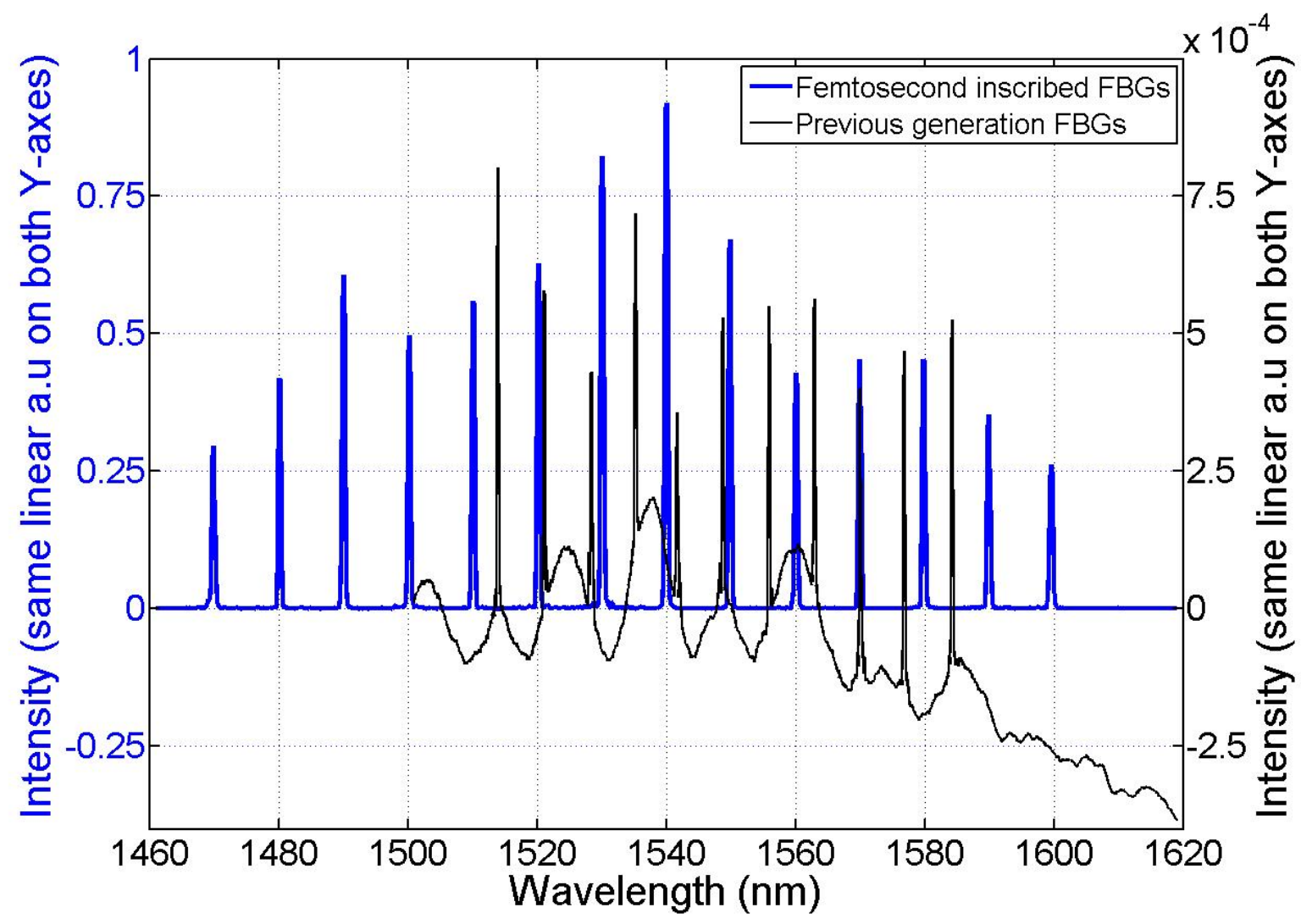

Figure 12 : (Blue) Typical spectrum obtained with femtosecond FBGs inscribed on a single optical fiber. Each one of the 14 Bragg peaks corresponds to one measurement spot along the fiber. (Black) Spectrum of the previous generation of FBGs (regenerated technology) already used during plasma operation in the WEST tokamak.

The calibration curve of a femtosecond FBG is displayed in Figure 13. This curve provides the Bragg peak wavelength as a function of temperature. When inversed, this curve is used for temperature measurements. The calibration curve presents a visible curvature showing that the peak shift tends to be larger as temperature increases. The grating sensitivity, derived from the calibration curve (in practice, the derivation is performed on a polynomial fit of the calibration curve), varies from $10 \mathrm{pm} /{ }^{\circ} \mathrm{C}$ at $70{ }^{\circ} \mathrm{C}$ up to $24 \mathrm{pm} /{ }^{\circ} \mathrm{C}$ at $1170{ }^{\circ} \mathrm{C}$ (cf. Figure 13 ). 


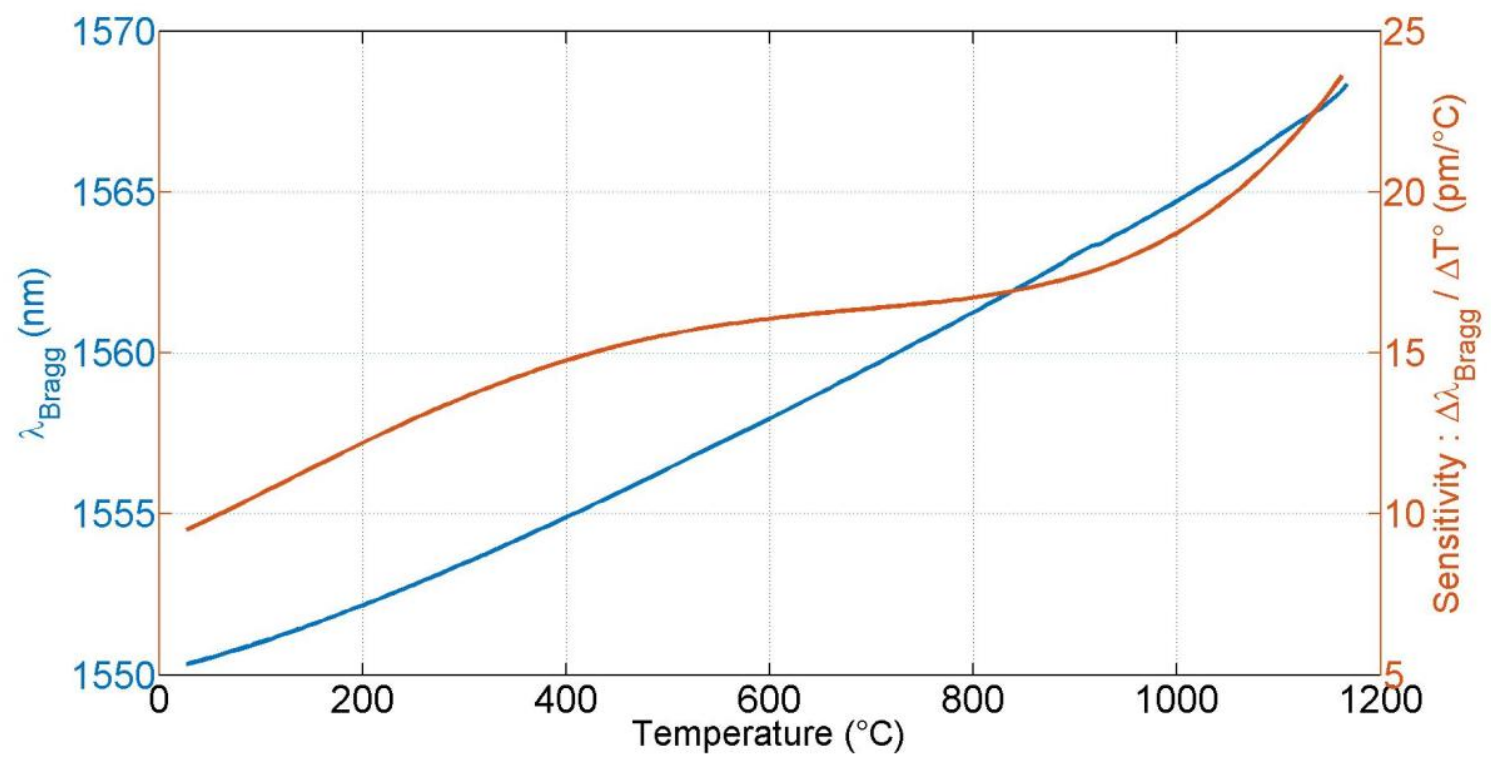

Figure 13 : Calibration curve of a femtosecond inscribed FBG and its sensitivity to temperature variations.

\subsection{FBGs integration}

The optic fiber is made with silica and has an outer diameter of $150 \mu \mathrm{m}$. It is enclosed in a stainlesssteel capillary of $350 \mu \mathrm{m}$ inner and $1 \mathrm{~mm}$ outer diameter to avoid fiber breaking under external mechanical constraints. The capillary is hermetically sealed at one extremity and the other extremity is open to the surrounding vacuum.

The capillary (containing the fiber) is fixed inside the groove with a high temperature ceramic adhesive (Ceramabond 571-VFG, Aremco) intended for use up to $1760^{\circ} \mathrm{C}$. The coefficient of thermal expansion of this glue is $12.6 \times 10^{-6}{ }^{\circ} \mathrm{C}^{-1}$ which is closer to that of stainless steel than that of tungsten.

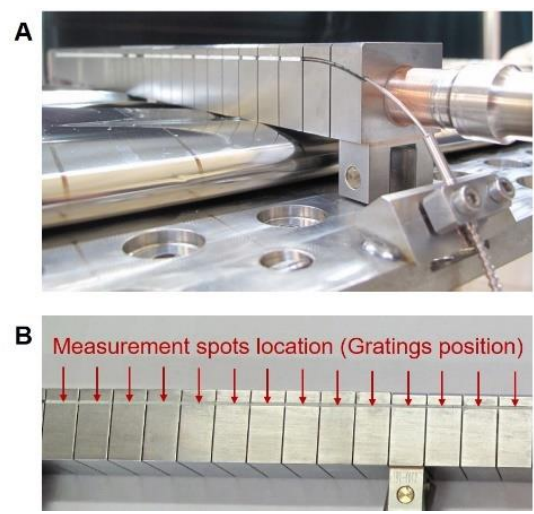

Figure 14: (A) Picture of an ITER-like PFU mounted on the WEST divertor. This PFU is machined with a groove running on its lateral face. The optic fiber enclosed in a stainless-steel capillary is visible as well as the white color glue used for the optic fiber fixation inside the groove. (B) Arrow pointing on gratings position along the lateral face of the PFU. Each grating is one measurement spot.

One optic fiber is inscribed with fourteen gratings regularly distributed over $17 \mathrm{~cm}$ distance to ensure one measurement spot for each monoblock (12.5 mm depth) as shown in Figure 14.

The vertical positioning of FBGs inside the PFU have been chosen by making a trade-off between maximizing the sensitivity to heat flux variations and limiting overheating above the groove and subsequent thermomechanical stresses in tungsten. On top of that, FBGs cannot withstand temperature 
above $1200{ }^{\circ} \mathrm{C}$ which prevents from positioning FBGs above this isotherm located a $5 \mathrm{~mm}$ below the surface on the lateral face of the PFU. The connection from the vacuum chamber to the FBG interrogator located in the electronic gallery (below WEST device) is unchanged regarding the previous FBG system installed in WEST (i.e. the previous generation of FBGs installed in tungsten-coated graphite PFU) [3].

\section{FBGs submitted to thermal gradients}

\subsection{Thermal gradient problematic}

The WEST divertor is configured in X-point which generates a sharp spatial variation of the heat flux pattern along the poloidal direction of the divertor. Extreme configurations could make the heat flux vary from $20 \mathrm{MW} / \mathrm{m}^{2}$ to few $\mathrm{MW} / \mathrm{m}^{2}$ over a $12 \mathrm{~mm}$ distance, i.e. the size of a monoblock, leading to strong thermal gradients along the fiber direction. These thermal gradients appear to be a major concern when designing FBGs as the temperature of the material could vary significantly over the grating length. The temperature measurement could therefore be affected by spectral artifacts. An example of artifact experienced with the previous generation of FBGs is displayed in Figure 15. In this example, a $3 \mathrm{~mm}$ long grating is submitted to approximately $20^{\circ} \mathrm{C} / \mathrm{mm}$ temperature gradient during the heating phase of plasma operation which results in the deformation of the Bragg peak. After the power cut-off, the cooling phase starts and the heat diffuses in the material so that the thermal gradients are removed rapidly and the peak recovers its original shape. One could notice that the peak recovery occurs at a higher temperature than peak collapsing occurs during the heating phase. This demonstrates that this peak collapsing effect is not related to grating degradation under high temperature but rather to temperature gradients. The principle underlying peak deformation is the loss of periodicity in the grating optical pitch becoming larger on one side of the grating than on the other. Light is reflected back from the grating with a broader spectral range and a lower peak amplitude leading to inaccurate peak tracking.

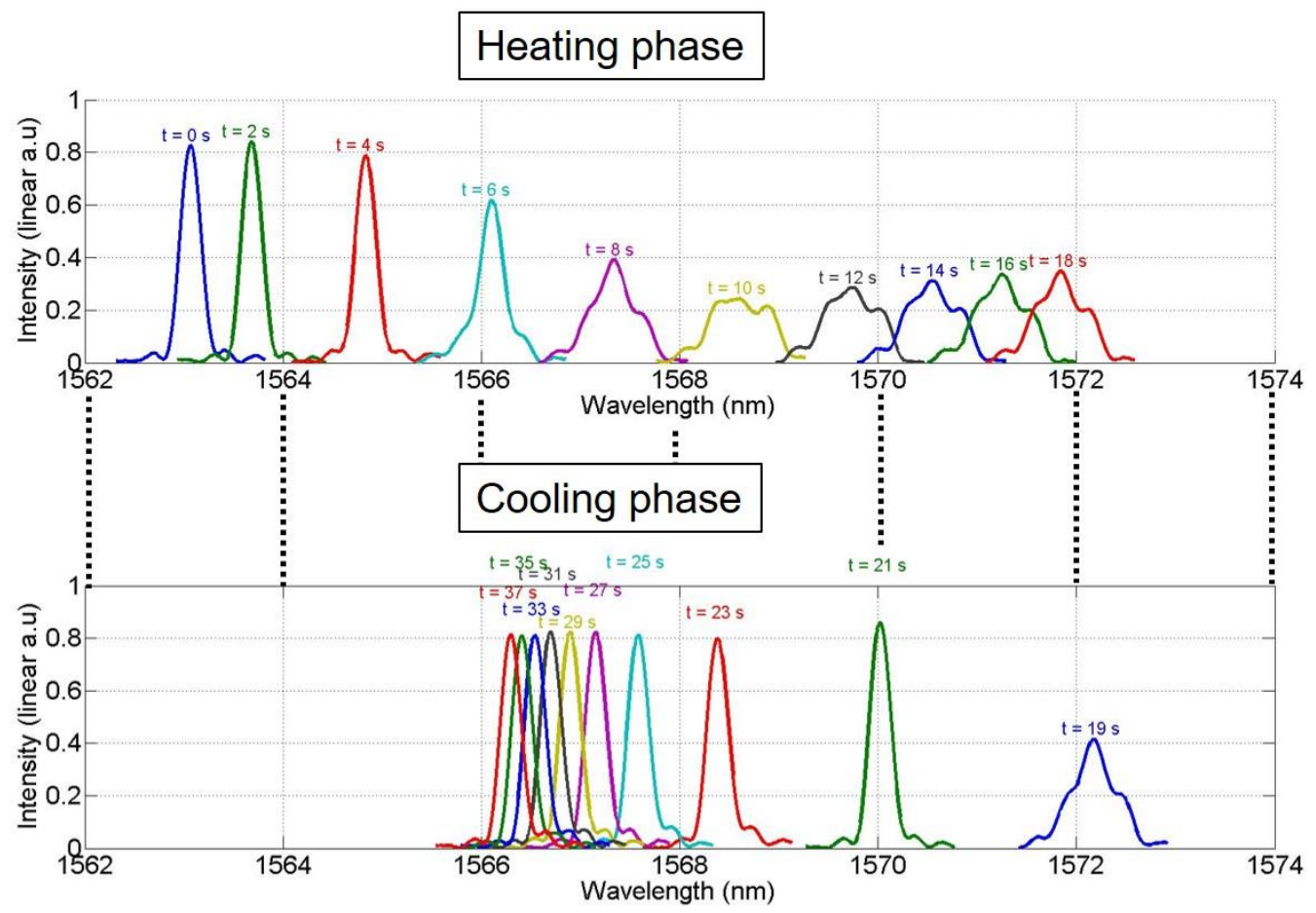

Figure 15: Peak collapsing and recovery observed during plasma operation in the WEST tokamak equipped with non-actively cooled PFUs. During the plasma heating phase, the Bragg peak collapses due to thermal gradients along the FBG. The cooling phase follows plasma cut off at $19 \mathrm{~s}$. Thermal gradients are removed consequently and the Bragg peak rapidly recovers its original shape. 


\subsection{Gradient strength simulation}

Finite element calculation was performed to evaluate thermal gradients in the fiber direction at the optical fiber location as depicted in Figure 16. In this simulation, the thermal conductivity of the glue is set to $0.57 \mathrm{~W} / \mathrm{m} / \mathrm{K}$ (typical order of magnitude for the type of ceramic adhesive used in this paper). The stainless-steel capillary is filled with silica glass. Heat flux varies linearly from 0 to $20 \mathrm{MW} / \mathrm{m}^{2}$ over a $12 \mathrm{~mm}$ distance which corresponds to the depth of a monoblock. The temperature present along the fiber is reported in Figure 16 showing a maximum gradient of $17^{\circ} \mathrm{C} / \mathrm{mm}$.
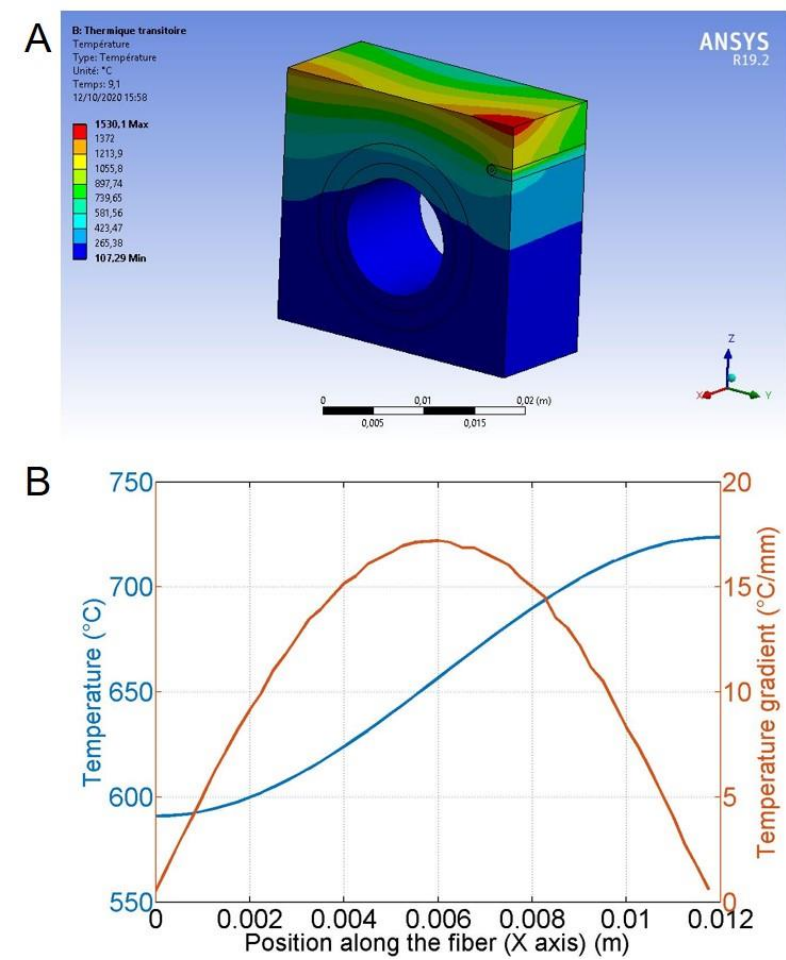

Figure 16: (A) Isotherms at steady state calculated on a single monoblock for a heat flux linearly increasing from 0 to 20 $M W / m 2$ over $12 \mathrm{~mm}$ in the $X$ direction. (B) Temperature variation along the optic fiber (in the $X$-axis direction) and temperature gradient in the optic fiber along the same direction.

\subsection{Theory on gradient effect}

By reducing the grating length, the optical pitch deviation due to thermal gradients is lowered and the Bragg peak is less prone to deformation. The spectral response of a Bragg peak under thermal gradients was numerically simulated for two different gratings length as shown in Figure 17. The grating is modeled by a series of successive reflecting layers regularly distributed every $\lambda_{\text {Bragg }} / 2$ over the desired grating length. The optical pitch is modified along the grating proportionally to the local temperature, which induces a variable phase shift of the reflected light at each layer. Each layer is assumed to reflect the same amount of light (no apodization). The spectral intensity of the Bragg peak is retrieved by summing the complex contribution of each layer to the total reflected light wave and finally by taking its squared magnitude. In this simulation, the dependence of the optical length with temperature, namely the grating sensitivity, is set to $20^{\circ} \mathrm{C} / \mathrm{mm}$. 

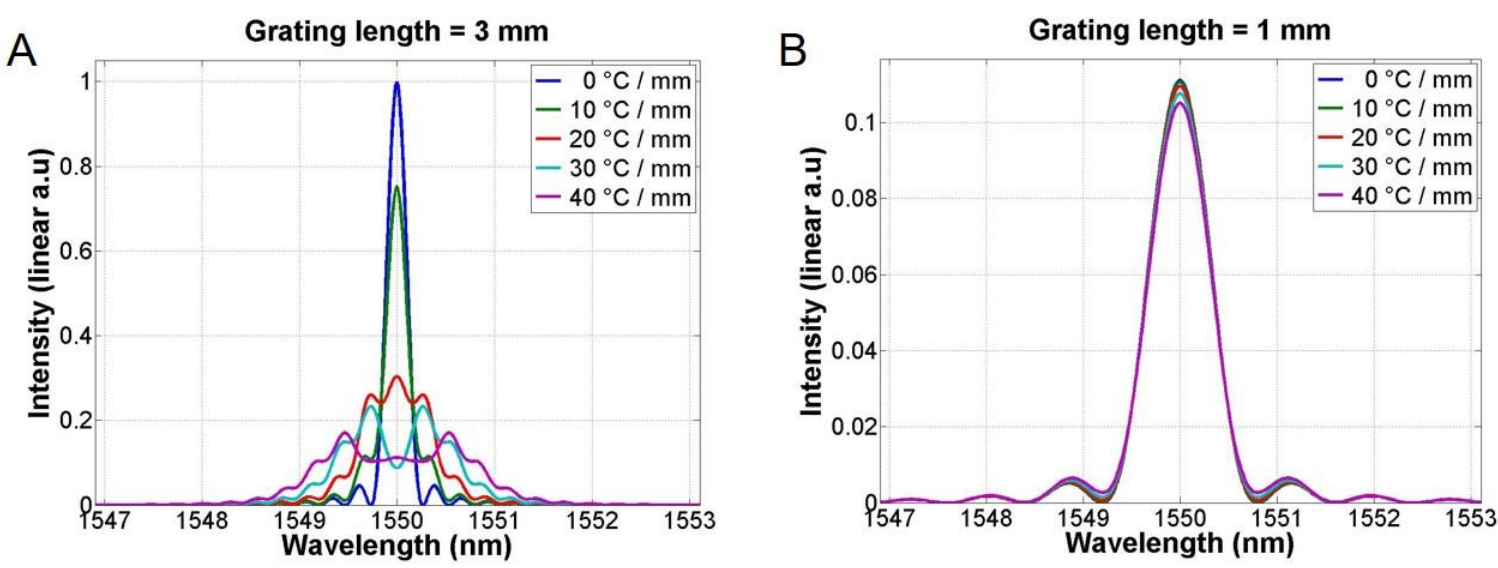

Figure 17 : Spectral simulation of a Bragg peak under thermal gradients of various magnitudes. (A) Grating length is $3 \mathrm{~mm}$. (B) Grating length is $1 \mathrm{~mm}$. In both $(A)$ and $(B)$, the optical length dependence with temperature, namely the grating sensitivity, is set to $20^{\circ} \mathrm{C} / \mathrm{mm}$.

The simulation shows that the Bragg peak for a 3mm long grating undergoes similar deformations as observed in Figure 15 while a $1 \mathrm{~mm}$ long grating undergoes little deformation even with $40^{\circ} \mathrm{C} / \mathrm{mm}$. As a first approximation, the spreading of the reflected wavelengths is proportional to the product: $[\mathrm{d} \lambda / \mathrm{dT}] .[\mathrm{dT} / \mathrm{dx}] . \mathrm{L}$, where $\mathrm{d} \lambda / \mathrm{dT}$ is the grating sensitivity, $\mathrm{dT} / \mathrm{dx}$ the gradient strength and $\mathrm{L}$ the grating length. However, in the absence of gradients, the peak width of a $1 \mathrm{~mm}$ long grating is larger and its peak intensity (in terms of light radiant power) is 9 times lower than a $3 \mathrm{~mm}$ long grating. In the model used for this simulation, the peak full width (defined as the distance between the first two minima) is inversely proportional to the grating length which corresponds to the weak grating case [12]. A convenient way to quantify the deformation of a peak is to calculate the ratio between the peak spreading in the presence of gradients and the peak width in the absence of gradients. Thus, deformation increases linearly with the grating sensitivity and the gradient strength. As the grating sensitivity tends to increase at higher temperatures (cf. Figure 13), larger deformations are expected at higher temperatures for a given gradient strength. The deformation also increases with the square of the grating length.

\subsection{FBGs specifications for thermal gradients}

The experimental spectra displayed in Figure 18 were obtained from femtosecond inscribed FBGs of various grating length. As expected from simulation, the Bragg peak of a $1 \mathrm{~mm}$ grating is wider and less intense than a $3 \mathrm{~mm}$ grating. The central wavelength of each Bragg peak was chosen so that the Bragg peaks are regularly distributed every $10 \mathrm{~nm}$ in the spectrum to avoid peak overlapping in the presence of thermal gradients. However, this $10 \mathrm{~nm}$ inter peak spacing could be reduced if the peak broadening is no more negligible as compared to $10 \mathrm{~nm}$. If we consider that peak overlapping starts at the peak base level, we should take into account the space taken by the peak full width (width of the peak base) in the inter peak spacing calculation. For a $3 \mathrm{~mm}$ grating, the inter peak spacing between the base of two consecutive peaks is $9 \mathrm{~nm}$ while for a $1 \mathrm{~mm}$ grating this spacing is reduced to $7 \mathrm{~nm}$. The inter peak spacing is essential to prevent peak overlapping in the presence of temperature variations along the fiber direction. The calibration curve (cf. Figure 13), taken in the high temperature range, shows that $9 \mathrm{~nm}$ spacing allows for a maximum temperature difference of $480^{\circ} \mathrm{C}$ before peaks start to overlap while 7 $\mathrm{nm}$ spacing limits the maximum temperature difference to $360{ }^{\circ} \mathrm{C}$. To reduce the actual temperature difference between two gratings having adjacent peaks, these two gratings are positioned as close as possible to each other. Extending this rule to the complete set of peaks results in positioning gratings along the fiber in the same order as their corresponding peak in the spectrum. For the configuration proposed in Figure 14, each grating belongs to one particular monoblock meaning that the temperature difference between two consecutive gratings is the temperature difference between the corresponding 
monoblocks. As shown in Figure 16, the temperature difference between two consecutive monoblocks could reach $600^{\circ} \mathrm{C}$, which is enough to induce overlapping in both spectrum of $3 \mathrm{~mm}$ and $1 \mathrm{~mm}$ gratings.

A

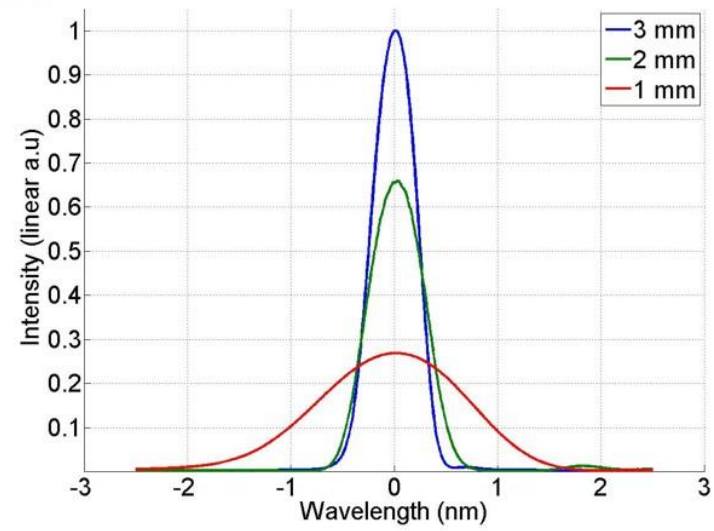

B

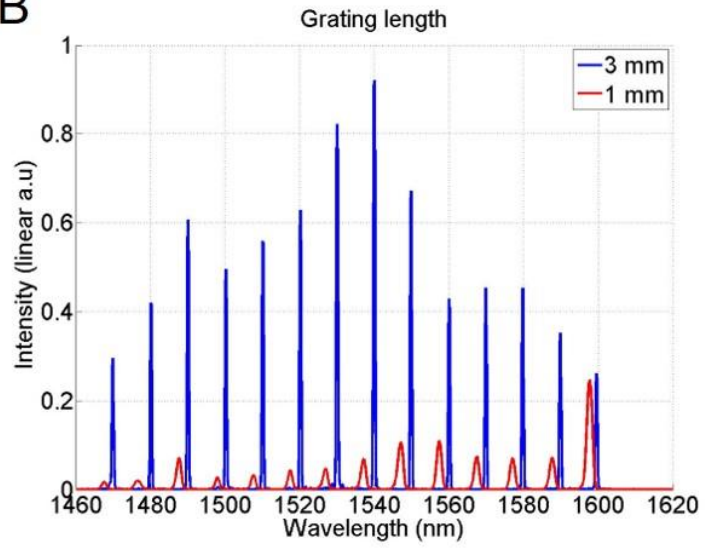

Figure 18: (A) Bragg peak obtained for various grating length. (B) Spectrum obtained for various grating length.

\section{Conclusion}

A PFC mock-up machined with a groove has been tested under HHF facility to assess the effect of the optical fiber integration on mono-blocks thermal behavior. The test demonstrates that machined monoblocks can withstand extreme heat flux $\left(20 \mathrm{MW} / \mathrm{m}^{2}\right)$ with $20 \%$ overheating as compared to intact monoblocks, which is consistent with numerical simulation. The transient thermal analysis shows that the PFC time response remained constant during the HHF test. No cracks or defects were observed following the test. These results suggest that the PFC thermal behavior is not affected by machining even after high heat flux exposure.

The temperature measured in the groove located $5 \mathrm{~mm}$ below the surface is consistent with theoretical prediction and is compatible with femtosecond FBG specifications $\left(1200{ }^{\circ} \mathrm{C}\right.$ at $\left.20 \mathrm{MW} / \mathrm{m}^{2}\right)$. However, the thermal and mechanical properties of the adhesive used for the fiber fixation were severely degraded after 300 cycles at $9 \mathrm{MW} / \mathrm{m}^{2}$ leading to at least $10 \%$ error and much longer time responses than that of the PFC. Furthermore, the time responses were much longer during the HHF test than during the nondestructive test performed at atmospheric pressure. Outgassing in vacuum environment and under high temperature is a possible reason to explain such discrepancies.

The femtosecond FBGs technology presents several advantages as compared to the older generation of FBGs used in WEST. First, they operate up to $1200{ }^{\circ} \mathrm{C}\left(800{ }^{\circ} \mathrm{C}\right.$ for the older generation $)$ with $\pm 0.02{ }^{\circ} \mathrm{C}$ error on temperature measurements $\left( \pm 1^{\circ} \mathrm{C}\right.$ for the older generation). The number of measurement spots is increased to 14 peaks per fiber (11 peaks per fiber for the older generation) mainly because the spectral range have been extended from $120 \mathrm{~nm}$ with the previous FBGs system to $160 \mathrm{~nm}$ with the new generation. The peak density over these spectral ranges allows for approximately $400{ }^{\circ} \mathrm{C}$ temperature difference between two adjacent monoblocks before peaks start to overlap. Such temperature difference is encountered for heat flux gradients exceeding $13 \mathrm{MW} / \mathrm{m}^{2}$ over the $12 \mathrm{~mm}$ depth of a monoblock. We have described the method to prevent peak deformation and ensure precise peak tracking capabilities under such heat flux gradients. 


\section{Acknowledgements}

We acknowledge the financial support of the Cross-Disciplinary Program on Instrumentation and Detection of CEA, the French Alternative Energies and Atomic Energy Commission.

\section{References}

[1] G Laffont et al 2013 Meas. Sci. Technol. 24094010

[2] M. Missirlian et al., Fusion Eng. Des. 89, 1048-1053 (2014).

[3] Y. Corre et al., Review of Scientific Instruments 89, 063508 (2018); doi: 10.1063/1.5024514

[4] X. Wang et al., Fusion Eng. Des. 150, 111378 (2020).

[5] A. Durocher, et al., Nucl. Fusion 47 (2007) 1682-1689

[6] S. Carpentier-Chouchana et al., Phys. Scr. T159, 014002 (2014), (7p.).

[7] T. Hirai et al., Nucl. Mater. Energy 000, 1-7 (2016).

[8] Team, I. (2013). Iter structural design criteria for in-vessel components (sdc-ic) appendix a:

Materials design limit data.

[9] J. Prokůpek, K. Samec, R. Jílek, P. Gavila, S. Neufuss, S. Entler, HELCZA - High Heat

Flux Test Facility for Testing ITER EU First Wall Components, Fusion Engineering and

Design 124, pp 187-190, 2017, doi: 10.1016/j.fusengdes.2017.03.059.

[10] D. Drouin, A. R. Couture, D. Joly, X. Tastet, V. Aimez, R. Gauvin, CASINO V2.42 --- A Fast and Easy-to-use Modeling Tool for Scanning Electron Microscopy and Microanalysis Users, Scanning 29, pp. 92-101, 2007, doi: 10.1002/sca.20000.

[11] N. Vignal, el al., Fusion Eng. Des. 88 (2013) 1818-1822

[12] Adriana Morana. Gamma-rays and neutrons effects on optical fibers and Bragg gratings for temperature sensors. Optics / Photonic. Université Jean Monnet - Saint-Etienne, 2013. English. NNT: 2013STET4023. tel-01064993 